\title{
Psychosocial, Lifestyle, and Body Weight Impact of COVID-19-Related Lockdown in a Sample of Participants with Current or Past History of Obesity in Spain
}

\author{
Amanda Jimenez ${ }^{1,2,3} \cdot$ Ana de Hollanda ${ }^{1,2,3} \cdot$ Eva Palou $^{4} \cdot$ Emilio Ortega $^{2,3,5} \cdot$ Alba Andreu $^{1} \cdot$ Judit Molero ${ }^{1}$. \\ Carla Mestre ${ }^{1}$. Ainitze Ibarzabal ${ }^{1} \cdot$ Amadeu Obach $^{1} \cdot$ Lilliam Flores $^{1,2,6} \cdot$ Silvia Cañizares $^{1} \cdot$ Jose Maria Balibrea $^{1}$. \\ Josep Vidal ${ }^{1,2,6} \cdot$ Joan Escarrabill ${ }^{4} \cdot$ Violeta Moize $^{1,2,6} \mathbb{C}$
}

Received: 25 November 2020 / Revised: 5 January 2021 / Accepted: 6 January 2021 / Published online: 23 January 2021

(C) The Author(s), under exclusive licence to Springer Science+Business Media, LLC part of Springer Nature 2021

\begin{abstract}
Purpose Home lockdown and isolation due to COVID-19 have been related to negative changes in mood, sleep, and eating behaviors. People with obesity are especially vulnerable to emotional eating and might be more prone to weight gain and negative outcomes during lockdown.

Materials and Methods Individuals scheduled for an appointment at the Obesity Unit of a Tertiary Hospital between March 16 and June $21(n=1230)$. An online survey was distributed on May 11. Multivariable logistic regression models and general linear models were used to assess the relationship between perceived COVID-19 threat, BS status, and outcome variables.

Results Of the 603 (72.0\% females, 39\% aged >55 years) respondents, 223 (36.9\%) were BS naïve (non-BS), 134 (22.2\%) underwent BS within the two previous years (BS<2y), and 245 (40.6\%) more than 2 years before (BS $>2 \mathrm{y})$. Participants worried about being infected by COVID-19 showed significantly larger changes in family contact $(p=0.04)$, mood $(p<0.01)$, sleep $(p<0.01)$, dietary habits $(p=0.05)$, purchases of unhealthy food $(p=0.02)$, snacking $(p=0.05)$, and physical activity $(p=0.02)$. Non-BS and $\mathrm{BS}>2 \mathrm{y}$ participants reported greater impact of lockdown in mood $(p<0.01)$, experienced more negative changes in dietary habits $(p<0.01)$, and had a higher likelihood for weight gain (OR: 5.61, 95\% CI: 3.0-10.46; OR: 5.45, 95\% CI: 2.87-10.35, respectively) compared to BS<2y. Conclusions COVID-19 pandemic is having a substantial negative impact in our population affected by obesity. During lockdown, people more than 2 years before BS behave like people without history of BS. Strategies addressed to prevent negative metabolic outcomes in this population are urgently needed.
\end{abstract}

Keywords Bariatric surgery $\cdot$ Weight gain $\cdot$ Eating behaviors $\cdot$ Physical activity $\cdot$ Concern $\cdot$ Mood

\author{
Violeta Moize \\ vmoize@clinic.cat \\ Amanda Jimenez \\ ajimene1@clinic.cat \\ Ana de Hollanda \\ amdehol@clinic.cat \\ Eva Palou \\ palou@clinic.cat \\ Emilio Ortega \\ eortega1@clinic.cat \\ Alba Andreu \\ aandreu@clinic.cat \\ Judit Molero \\ jmolero@clinic.cat \\ Carla Mestre \\ cmestre@clinic.cat
}

\author{
Ainitze Ibarzabal \\ aibarza@clinic.cat \\ Amadeu Obach \\ aobach@clinic.cat \\ Lilliam Flores \\ 1flores@clinic.cat \\ Silvia Cañizares \\ scanizar@clinic.cat \\ Jose Maria Balibrea \\ balibrea@clinic.cat \\ Josep Vidal \\ jovidal@clinic.cat \\ Joan Escarrabill \\ escarrabill@clinic.cat
}

Extended author information available on the last page of the article 


\section{Introduction}

SARS-CoV-2 infection (COVID-19) emerged in Wuhan, China, in December 2019. The infection spread rapidly worldwide, causing an unprecedented burden on health care systems [1]. As an urgent measure to limit the spread of the disease, many governments worldwide established quarantine, forcing millions of people to stay indoors and maintain isolation for a long period of time [2].

Lockdown may lead to lifestyle modifications favoring weight gain and its undesirable metabolic consequences. Decrease in leisure time activities, boredom, increase in time spent watching TV, and easy access to food may favor snacking and overeating $[3,4]$. Besides, as result of confinement, regular physical activity may be harder to maintain, contributing to a positive energy balance. On the other hand, home lockdown and isolation due COVID-19 have been related to psychological distress, mood, and sleep disturbances [5-10] which in turn may negatively impact eating behaviors [11-15]. Indeed, most previous surveys conducted in general population in the context of the COVID-19 outbreak showed significant declines in physical activity and healthy dietary patterns in a substantial proportion of individuals [16-20].

People with obesity could be considered more susceptible to the negative outcomes of lockdown. This population is especially vulnerable to psychological distress, emotional eating, and eating disorders and thus may be more prone to weight gain $[12,21]$. Furthermore, there is an additional burden for some, associated to the disruption of their usual chronic care or delay of scheduled bariatric surgery due rearrangements in hospital activity [22]. Only one previous study, including 123 participants, has assessed the psychological and dietary impact of home lockdown in people with severe obesity [23]. In this study, conducted during the first 2 weeks of confinement in Texas, the vast majority of participants reported increased anxiety and depression. Around 70\% felt it was more challenging to achieve weight goals, and approximately $60 \%$ reported emotional eating. However, the impact of confinement on body weight was not assessed, and the sample was mainly composed of highly educated participants with highincome levels, which may not be representative of an average population with obesity [23].

Our main objective was to assess the extended ( 9 weeks after the stay-at-home order) psychosocial, lifestyle, and body weight impact of COVID-19-related lockdown in a Spanish sample of participants with present or past history of severe obesity. As secondary aims, we examined whether perceived COVID threat and bariatric surgery modulated this response.

\section{Methods}

All patients scheduled to attend our obesity clinic during the COVID-19 lockdown (from March 16 to June 21), and whose follow-up appointments during this period were canceled were reached via e-mail and invited to complete the survey of our cross-sectional study. Demographic information was collected to characterize the subject population including age, gender, marital status, educational level, and employment status. Subjects were categorized as non-bariatric (non-BS) or bariatric patients according to past history of this treatment modality for obesity. Bariatric surgery patients were further subdivided according to the time elapsed from surgery ( $<2$ years $[\mathrm{BS}<2 \mathrm{y}]$ or $>2$ years $[\mathrm{BS}>2 \mathrm{y}]$ ). The $e$-survey used in our study was developed ad hoc for the present study, following the completion of three e-focus groups with a total of 10 participants aiming to identify the most relevant categories to include in the e-survey. The main categories identified through the e-focus groups were included in the survey, distributed in 4 main meta-categories, which were (1) COVID19-related concern; (2) mood, sleep, social, and family contacts; (3) dietary habits and physical activity; and (4) obesity treatment and weight change. The e-survey was written in Spanish, distributed through institutional e-mail and took less than $10 \mathrm{~min}$ to complete. A translation of the e-survey into English can be found in the Supplementary material section.

The study took place 9 weeks after Spain declared a national state of alarm and issued the stay-at-home order because of the COVID-19 outbreak. The survey was sent to all patients on May 11, and they were given a 1-week period to respond. All procedures performed in studies involving human participants were in accordance with the ethical standards of the institutional and/or national research committee and with the 1964 Helsinki declaration and its later amendments or comparable ethical standards. Participants were not compensated for their participation. The internal review board approved the study, and informed consent was obtained from all individual participants included in the study before completing the $e$ survey.

\section{Statistical Analyses}

Data are presented as mean \pm standard deviation (SD) or as percentage when appropriate. Baseline differences between groups were assessed by analyses of variance (quantitative variables) or $X^{2}$ test (categorical variables). Independent associations between COVID-19-related concern and sociodemographic conditions were tested using multivariable logistic regression analyses. Differences in mean scores for psychosocial and lifestyle variables across COVID-perceived concern, susceptibility and severity, and BS status categories were tested using the analysis of covariance test. Likelihood for presenting substantial changes in psychosocial and lifestyle variables across COVID-related concern, susceptibility, severity, and BS status categories was tested using multivariable logistic regression models. All models included sociodemographic characteristics as covariates. Substantial changes 
were arbitrary defined as score $\geq 5$. Statistical significance was set at $p<0.05$ (two tailed). Statistical analysis was performed using IBM SPSS version 22.0.

\section{Results}

A study flow chart is displayed in Supplementary Fig. 1. A total of 1230 eligible patients were contacted by e-mail, and 720 patients completed and sent back the survey before 1 week. Of those, 117 were excluded because of missing data required for the pre-specified analyses (including sociodemographic conditions and the state of bariatric surgery). The final sample included 603 respondents $(49.0 \%)$.

Table 1 summarizes the subjects' demographic and clinical characteristics. A total of $372(61.7 \%)$ reported history of BS. Among BS participants, the majority (65.8\%) had BS more than 2 years before the COVID19 pandemic $(B S>2 y)$. BS $>2 y$ participants were older and were less frequently active workers compared to those who underwent BS during the 2 years before the pandemic $(\mathrm{BS}<2 \mathrm{y})$ or the non-BS group. The proportion of females was higher among $\mathrm{BS}<2 \mathrm{y}$ and $\mathrm{BS}>2$ years than among non-operated participants. Only 258 $(42.7 \%)$ of 603 respondents reported their current body weight and body mass index (BMI). BMI was lower in the $\mathrm{BS}<2 \mathrm{y}$ group, compared to the $\mathrm{BS}>2 \mathrm{y}(p=0.041)$ or the non-BS group $(p<0.01)$. BMI was also lower in $\mathrm{BS}>2 \mathrm{y}$ compared to non-BS participants $(p<0.01)$.

\section{COVID-19-Perceived Threat and Psychological and Alimentary Impact of Lockdown in Patients with Current or Past History of Obesity}

\section{Concern}

As shown in Fig. 1a, the majority of participants (77.1\%) were worried about contracting COVID-19, while only a minority were not worried at all (2.0\%). Almost half (45\%) considered themselves prone to getting infected (rated as "likely"), and more than one-third thought that in case of SARS-CoV-2 infection, they would develop a life-threatening $(14.8 \%)$ or serious disease $(32.7 \%)$.

Supplementary Table 1 displays the proportion of respondents for each concern, susceptibility, and severity categories across demographic and socioeconomic conditions. Higher concern for contracting COVID-19 was independently related to female gender (OR: 1.97 (95\%CI: 1.21-3.20) while only being an active worker was associated with higher selfestimated risk for being infected by SARS-CoV-2 (OR: 2.27 (95\%CI: 1.30-4-06). None of the other demographic or socioeconomic factors, including BS status, influenced the perceived concern, perception of susceptibility to disease, or severe disease in case of infection. Inclusion of BMI (available in 258 participants) in these models did not modify the association between higher concern and female gender nor the association between higher self-estimated risk for being infected and active working status. BMI was unrelated to perceived COVID-19 threat (concern: $p=0.78$, susceptibility: $p=0.85$, severity: $p=0.27$ ).

Table 1 Socio-demographic characteristics of respondents

\begin{tabular}{|c|c|c|c|c|c|c|c|}
\hline & \multirow[t]{2}{*}{$\begin{array}{l}N \text { with available } \\
\text { data }\end{array}$} & \multirow[t]{2}{*}{ Categories } & \multirow[t]{2}{*}{$\begin{array}{l}\text { Whole cohort } \\
(n=603)\end{array}$} & \multicolumn{2}{|l|}{$\begin{array}{l}\text { Bariatric patients } \\
(n=372)\end{array}$} & \multirow{2}{*}{$\begin{array}{l}\text { Non-bariatric } \\
\text { patients } \\
(n=223)\end{array}$} & \multirow[t]{2}{*}{$p$ value } \\
\hline & & & & $\begin{array}{l}<2 \text { years since surgery } \\
(n=135)\end{array}$ & $\begin{array}{l}>2 \text { years since surgery } \\
(n=245)\end{array}$ & & \\
\hline \multirow[t]{3}{*}{ Age, years $(n, \%)$} & \multirow[t]{3}{*}{601} & $18-44$ & $168(28.0)$ & $51(38.3)$ & $53(21.7)$ & $64(28.1)$ & \multirow[t]{3}{*}{0.001} \\
\hline & & $44-54$ & $195(32.4)$ & $47(35.3)$ & $78(32.0)$ & $70(31.4)$ & \\
\hline & & $\geq 55$ & $238(39.6)$ & $36(26.6)$ & $113(46.3)$ & $89(39.9)$ & \\
\hline \multirow[t]{2}{*}{ Gender $(n, \%)$} & \multirow[t]{2}{*}{600} & Females & $434(72.0)$ & $104(77.6)$ & $195(79.6)$ & $135(60.5)$ & \multirow[t]{2}{*}{$<0.001$} \\
\hline & & Males & $166(27.5)$ & $29(21.6)$ & $50(20.4)$ & $87(39.2)$ & \\
\hline $\begin{array}{l}\text { Self-reported BMI } \\
\qquad\left(\mathrm{Kg} / \mathrm{m}^{2}\right)\end{array}$ & 258 & & $34.2 \pm 7.0$ & $30.9 \pm 6.0$ & $33.4 \pm 6.1$ & $37.6 \pm 7.3$ & $<0.001$ \\
\hline \multirow[t]{2}{*}{ Marital status $(n, \%)$} & \multirow[t]{2}{*}{598} & Single/divorced & $199(33.0)$ & $35(26.5)$ & $84(34.6)$ & $80(36.0)$ & \multirow[t]{2}{*}{0.161} \\
\hline & & Married & $399(66.7)$ & $97(73.5)$ & $160(65.3)$ & $142(64.0)$ & \\
\hline \multirow{3}{*}{$\begin{array}{l}\text { Education level } \\
\qquad(n, \%)\end{array}$} & \multirow[t]{3}{*}{576} & Secondary or less & $175(30.4)$ & $44(34.4)$ & $73(30.9)$ & $58(27.3)$ & \multirow[t]{3}{*}{0.261} \\
\hline & & Some college & $271(44.9)$ & $63(49.2)$ & $110(46.6)$ & $98(46.4)$ & \\
\hline & & College graduate & $130(21.6)$ & $21(16.4)$ & $53(22.5)$ & $56(26.5)$ & \\
\hline \multirow[t]{2}{*}{ Employed $(n, \%)$} & \multirow[t]{2}{*}{455} & Yes & $338(74.3)$ & $85(86.7)$ & $139(73.9)$ & $114(67.9)$ & \multirow[t]{2}{*}{0.003} \\
\hline & & No & $117(25.7)$ & $13(11.2)$ & $50(26.4)$ & $54(32.1)$ & \\
\hline
\end{tabular}

Data is expressed as $n, \%$, or as mean \pm standard deviation

$B M I$ body mass index 
a

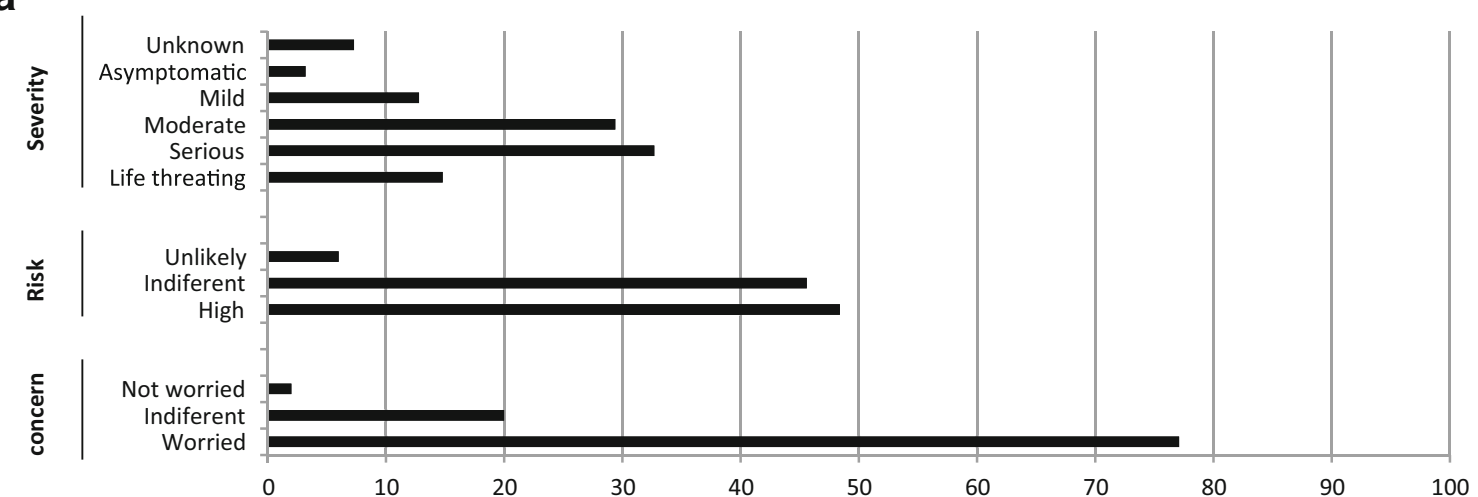

b

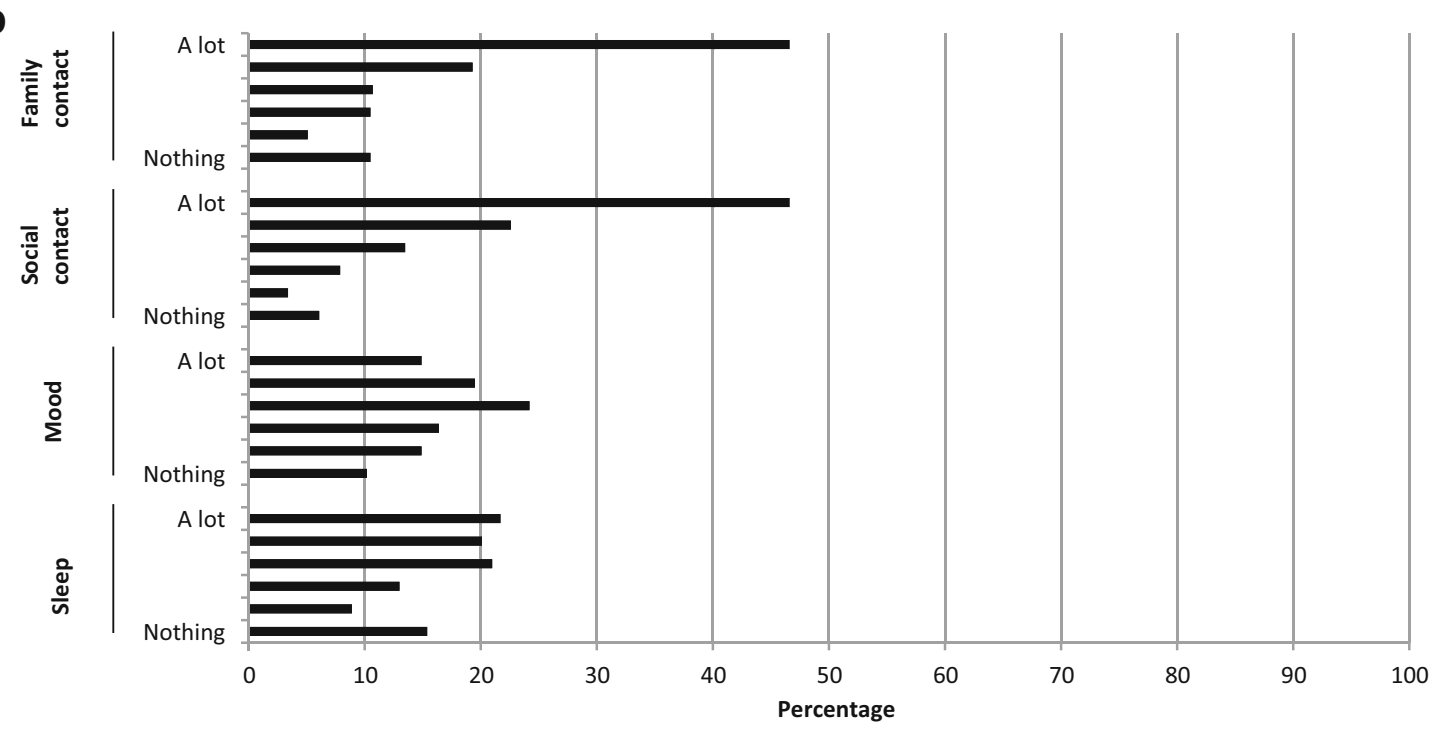

Fig. 1 (a) COVID-19-perceived threat and psychological impact of lockdown and (b) impact of COVID-19 related on mood, sleep, and family and social contact in patients with current or past history of obesity

\section{Mood, Sleep, and Family and Social Contact}

As shown in Fig. 1b, more than one-third of participants reported substantial impact, score 5 to 6 , of lockdown on mood (33.9\%) and sleep (40.9\%). The majority also referred substantial changes in their usual family $(63.2 \%)$ and social relationships (69.2\%). Participants with higher scores for changes in social relationships or family contact rated higher for changes in $\operatorname{mood}(r: 0.30, p<0.01$ and $\mathrm{r}: 0.20, p<0.01$, respectively) and sleep ( $r: 0.20, p<0.01$ and $r: 0.14, p<0.01)$.

\section{Dietary Habits and Weight Gain}

As shown in Fig. 2, more than one-third of participants $(32.5 \%)$ substantially changed their dietary habits (score: 5 or 6), while only $17.8 \%$ referred no impact of confinement in their regular dietary intake (score: 1). Most respondents said that confinement did not $($ score $=1)$ or slightly changed $($ score $=2)$ their average consumption of sugary beverages (75.0\%) or alcohol $(81.4 \%)$. Only $15.8 \%$ of respondents rated
5 or 6 for changes in standard alimentary purchases towards unhealthy and comfort food, while $32.5 \%$ referred no modifications. One-fifth $(19 \%)$ of participants said that snacking substantially increased (score $=5$ or 6 points) during the home lockdown, while $26 \%$ reported no changes. Overall physical activity was considered the more affected practice as more than half of participants related substantial changes in this item $(38.5 \%$ rated as 6 and $22.5 \%$ rated as 5$)$.

Participants with more extensive changes in sleep, mood, and social or family contact scored higher for changes in dietary habits, consumption of sugary beverages or alcohol, purchase of unhealthy foods, and snacking (Supplementary Table 2).

The majority of participants (52.2\%) gained weight during the quarantine period. Supplementary Table 3 displays the proportion of respondents with weight gain across demographic and socioeconomic conditions.

Participants with weight gain rated higher for changes in $\operatorname{mood}(4.0 \pm 1.5$ vs. $3.3 \pm 1.5, p<0.01)$, sleep $(4.1 \pm 1.6$ vs. 3.5 $\pm 1.8, p<0.01)$, and social relationships $(5.0 \pm 1.4$ vs. $4.7 \pm 1.6$, $p=0.02$ ) than those without. Similarly, participants with 


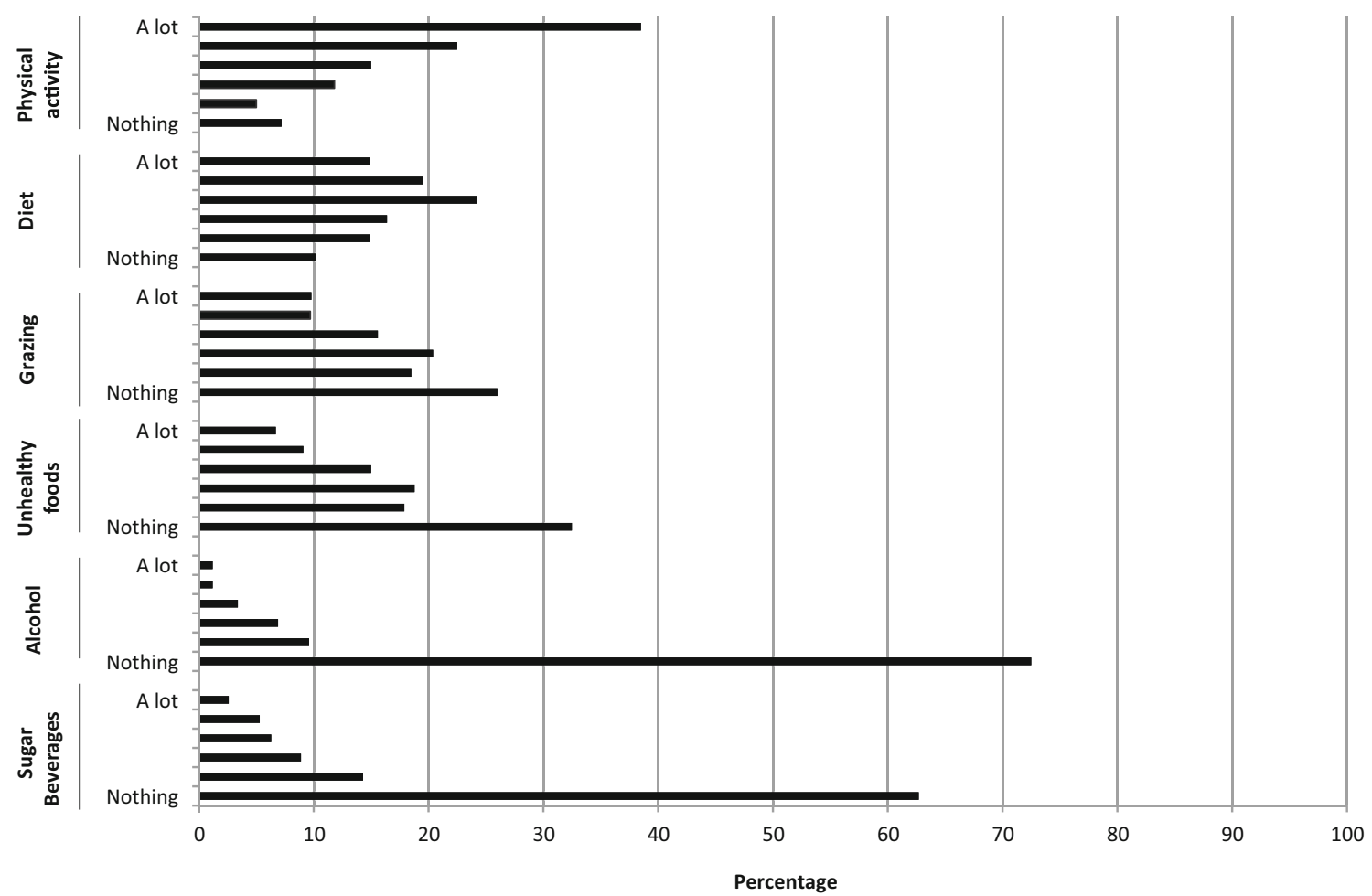

Fig. 2 Impact of COVID-19-related lockdown on dietary habits and physical activity in patients with current or past history of obesity

weight gain rated higher for changes in standard dietary habits ( $4.1 \pm 1.5$ vs. $2.5 \pm 1.5, p<0.01)$, physical activity (5.0 \pm 1.4 vs. $4.1 \pm 1.6, p<0.01)$, purchase of unhealthy and comfort foods ( $3.3 \pm 1.6$ vs. $2.0 \pm 1.2, p<0.01)$, increase in consumption of sugary beverages $(2.1 \pm 1.5$ vs. $1.5 \pm 1.0, p<0.01)$ or alcohol (1.6 \pm 1.2 vs. $1.3 \pm 0.7, p<0.01$ ), and snacking ( $3.6 \pm 1.6$ vs. 2.1 $\pm 1.3, p<0.01)$.

\section{Influence of Perceived COVID-19 Threat on Mood, Sleep, Normal Relationships, Dietary Habits, Physical Activity, and Weight Gain}

Multivariable analyses assessing the association between perceived COVID-19 threat and changes in social and family contact, sleep, mood, alimentary habits, physical activity, and weight gain are shown in Table 2 and Table 3.

Participants worried about being infected by COVID-19 showed larger changes in family contact, mood, sleep, dietary habits, purchase of unhealthy food, snacking, and physical activity and had a twofold higher probability for presenting substantial changes in these variables (Table 2 and Table 3). These associations were independent of socioeconomic and demographic factors, including BS status. Higher fear of severe disease in case of infection negatively impacted mood scores and consumption of sugary beverages (Table 2 and Table 3). However, perceived COVID-19 concern, susceptibility, and severity were not directly associated with weight gain.

\section{Influence of BS Status on Mood, Sleep, Social and Family Relationships, Dietary Habits, Physical Activity, and Weight Gain}

Multivariable analyses assessing the association between BS status and changes in social and family contact, sleep, mood, alimentary habits, and physical activity are shown in Table 4.

Non-BS and BS $>2 y$ participants, as compared to $\mathrm{BS}<2 \mathrm{y}$, presented larger impact of lockdown in mood and experienced more negative changes in regular dietary behaviors, including consumption of sugary beverages or alcohol, purchase of unhealthy foods, and snacking (Table 4). Inclusion of changes in mood as covariate in these models did not modify the protective effects of $\mathrm{BS}<2 \mathrm{y}$ on disrupted eating behaviors (data not shown).

BS status within the two previous years emerged as a protective factor for weight gain during lockdown. NonBS participants (OR: 5.61, 95\% CI: 3.0-10.46) or those who underwent surgery more than 2 years before (OR: 5.45, 95\% CI: 2.87-10.35) showed a fivefold likelihood for presenting weight gain compared to those who underwent surgery within the two previous years independently of demographic and socioeconomic factors and of perceived COVID-19 threat. Inclusion of changes in mood did not modify this association. 


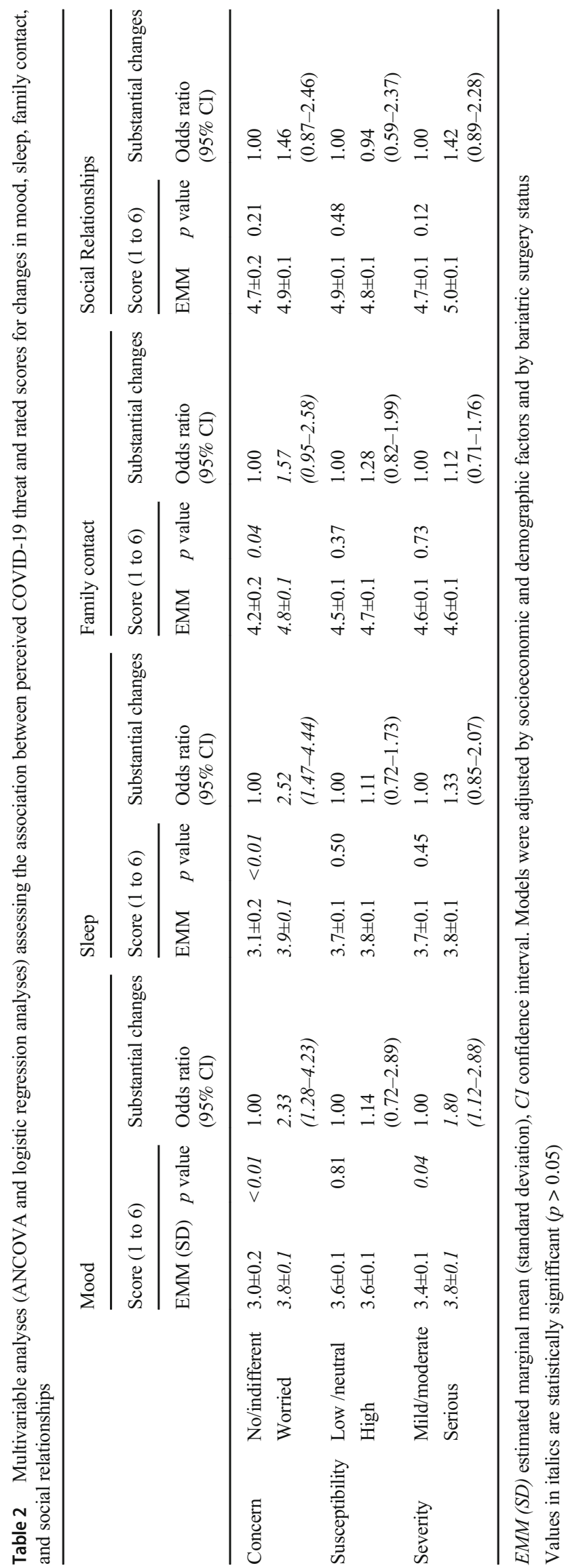

\section{Discussion}

In this cross-sectional survey, including more than 600 participants with current or past history of obesity, we describe a high level of concern about the COVID-19 pandemic across most respondents. The majority also experienced significant disturbances in mood and sleep and perceived a substantial disruption in their usual family and social relationships. Furthermore, physical activity and dietary habits were considerably affected. All these factors resulted in or contributed to weight gain in a large proportion of the sample. Participants with the highest level of concern for contracting the disease were at increased risk of mood and sleep alterations and negative changes in eating behaviors. Only participants who underwent BS within the 2 years before the quarantine, but not those operated more than 2 years before, were partially protected from these issues and weight gain.

More than $70 \%$ of our sample was worried about contracting COVID-19. This rate was higher than that reported in other studies [6-9, 24]. It should be emphasized that at the time of our study, Spain had been under a nationwide state of alert for more than 9 weeks, and more than 230,000 cases of COVID-19 and more than 18,000 deaths due to the disease were registered in our country (https://www.isciii.es). In most previous studies, surveys were sent at the beginning of the pandemic when very few cases and deaths were reported and lockdown measures were just starting [6-9, 24]. Thus, our sample may reflect a more chronic situation in which consequences of lockdown and isolation were extended. Alternatively, it could be possible that particular characteristics of our cohort may have influenced the perceived threat of disease. Of note, obesity and comorbid conditions highly prevalent among people with obesity, such as hypertension and T2D, have been identified and communicated through media as risk factors for worse outcomes [25-27]. We observed a substantial impact of lockdown on social and family relationships, mood, sleep, physical activity, and dietary habits. On the contrary, very few participants reported significant increase in alcohol consumption or sugary beverages. Moreover, within limitations (especially that it was a self-reported and qualitative measure), our survey revealed that weight gain occurred in an extremely high percentage of participants (more than $50 \%$ overall and near to $60 \%$ for those who underwent BS more than 2 years before or those never operated).

Few studies have evaluated the impact of home lockdown on dietary habits [16-20,23] and even less have studied changes in body weight $[17,20,21]$. To our knowledge, among those studies, only one was conducted in people with severe obesity [23]. In agreement with our data, most of them showed a significant negative impact of lockdown on dietary habits and consumption of unhealthy food and snacks $[16,17$, 19-21, 23]. Nonetheless, changes towards healthier diet 


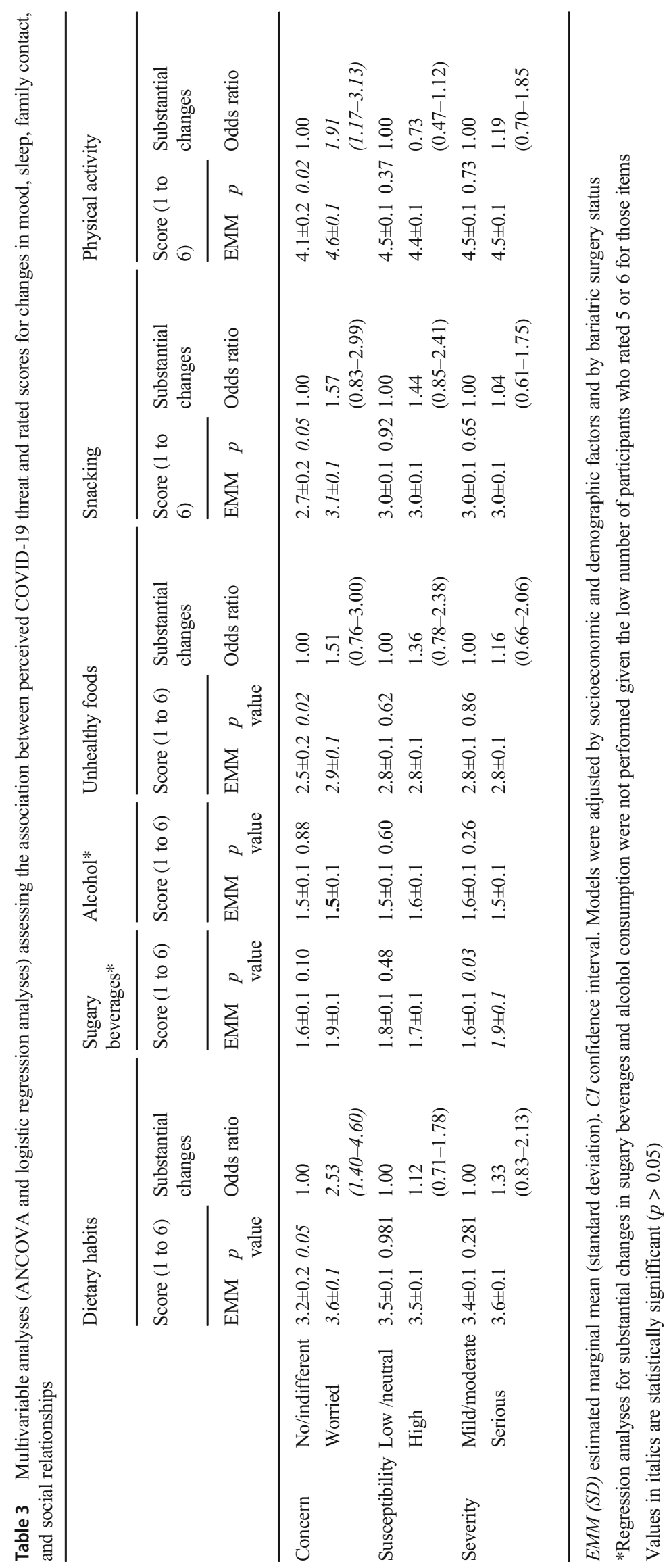


Table 4 Multivariable analyses (ANCOVA and logistic regression analyses) assessing the association between bariatric surgery status and rated scores for changes in mood, sleep, family contact, social relationships, and dietary habits

\begin{tabular}{|c|c|c|c|c|c|}
\hline & & \multicolumn{4}{|c|}{ Bariatric surgery status } \\
\hline & & $<2$ years & $>2$ years & Non-operated & $p$ value \\
\hline \multirow[t]{2}{*}{ Mood } & Score $(1$ to 6$)(E M M \pm S D)$ & $2.8 \pm 0.2$ & $3.6 \pm 0.1$ & $3.8 \pm 0.1$ & $<0.01$ \\
\hline & Substantial changes (OR, CI 95\%) & Reference & $1.76(0.92-3.35)$ & $2.73(1.41-5.31)$ & - \\
\hline \multirow[t]{2}{*}{ Sleep } & Score $(1$ to 6$)(E M M \pm S D)$ & $3.5 \pm 0.2$ & $3.7 \pm 0.1$ & $3.9 \pm 0.1$ & 0.28 \\
\hline & Substantial changes (OR, CI 95\%) & Reference & $1.50(0.83-2.71)$ & $2.10(1.13-3.89)$ & - \\
\hline \multirow[t]{2}{*}{ Social relationships } & Score $(1$ to 6$)(E M M \pm S D)$ & $4.5 \pm 0.2$ & $4.7 \pm 0.1$ & $4.6 \pm 0.1$ & 0.45 \\
\hline & Substantial changes (OR, CI 95\%) & Reference & $1.22(0.68-2.21)$ & $1.04(0.57-1.89)$ & - \\
\hline \multirow[t]{2}{*}{ Family contact } & Score (1 to 6) $(\mathrm{EMM} \pm \mathrm{SD})$ & $4.6 \pm 0.2$ & $5.0 \pm 0.1$ & $4.8 \pm 0.1$ & 0.13 \\
\hline & Substantial changes (OR, CI 95\%) & Reference & $1.44(0.80-2.61)$ & $1.28(0.69-2.38)$ & - \\
\hline \multirow[t]{2}{*}{ Dietary habits } & Score $(1$ to 6$)(E M M \pm S D)$ & $2.8 \pm 0.2$ & $3.6 \pm 0.1$ & $3.6 \pm 0.1$ & $<0.01$ \\
\hline & Substantial changes (OR, CI 95\%) & Reference & $2.32(1.21-4.45)$ & $2.38(1.36-8.69)$ & - \\
\hline \multirow[t]{2}{*}{ Consumption of sugary beverages* } & Score $(1$ to 6$)(E M M \pm S D)$ & $1.4 \pm 0.1$ & $1.8 \pm 0.1$ & $1.9 \pm 0.1$ & 0.02 \\
\hline & Substantial changes (OR, CI 95\%) & - & - & - & - \\
\hline \multirow[t]{2}{*}{ Consumption of alcohol* } & Score $(1$ to 6$)(E M M \pm S D)$ & $1.2 \pm 0.1$ & $1.6 \pm 0.1$ & $1.7 \pm 0.1$ & 0.03 \\
\hline & Substantial changes (OR, CI 95\%) & - & - & - & - \\
\hline \multirow[t]{2}{*}{ Unhealthy food purchase } & Score $(1$ to 6$)(E M M \pm S D)$ & $2.2 \pm 0.2$ & $3.0 \pm 0.1$ & $2.9 \pm 0.1$ & $<0.01$ \\
\hline & Substantial changes (OR, CI 95\%) & Reference & $3.83(1.56-9.43)$ & $3.44(1.36-8.69)$ & - \\
\hline \multirow[t]{2}{*}{ Snacking } & Score $(1$ to 6$)(\mathrm{EMM} \pm \mathrm{SD})$ & $2.6 \pm 0.2$ & $3.2 \pm 0.1$ & $3.0 \pm 0.1$ & 0.02 \\
\hline & Substantial changes (OR, CI 95\%) & Reference & $2.15(1.03-4.94)$ & $1.99(0.91-4.34)$ & - \\
\hline \multirow[t]{2}{*}{ Physical activity } & Score (1 to 6$)(E M M \pm S D)$ & $4.3 \pm 0.2$ & $4.6 \pm 0.1$ & $4.5 \pm 0.1$ & 0.53 \\
\hline & Substantial changes (OR, CI 95\%) & Reference & $1.28(0.72-2.27)$ & $1.19(0.66-2.14)$ & \\
\hline
\end{tabular}

Models were adjusted by socioeconomic and demographic characteristics and by perceived concern, susceptibility, and severity in case of being infected by SARS-CoV-2

*Regression analyses were not performed for sugary beverages and alcohol consumption given the very low number of respondents who rated for substantial changes in these items

$E M M$ estimated marginal mean, $S D$ standard deviation, $O R$ odds ratio, $C I$ confidence interval

Values in italics are statistically signifficant $(p>0.05)$

patterns were also described [18]. In this regard, the largest $(n=7514)$ web-based survey conducted to date, also in adult Spanish population, showed an increase in Mediterranean Diet adherence [18].

In contrast, the proportion of participants reporting weight gain in these studies was much lower (ranging between 12.6 and $30 \%)$ than that observed in our cohort $(52 \%)[20,21]$. Differences in lockdown duration ( 9 weeks vs. 3 weeks) and conditions (less restrictive in Poland) may have contributed to the more substantial impact observed in our cohort. Indeed, only Di Renzo et al., in an Italian survey performed 7 weeks after starting of confinement, reported a similar proportion of participants who gained weight (48\%) compared to our observations [17]. Also, the particular characteristics of our cohort (i.e., obesity) may have influenced the proportion of patients reporting weight gain. Of note, in the study by Sidor et al., participants with obesity ( $n=94,8.6 \%$ of the sample) were more vulnerable to negative changes in dietary habits and more prone to gain weight than those with normal weight
[17]. In any case, this data supports the significant detrimental consequences of extended lockdown on body weight, especially in subjects afflicted by obesity.

In our sample, a high level of concern for being infected for SARS-CoV-2 negatively modulated psychological and dietary response to lockdown. Participants with the highest level of concern showed more extensive changes not only in social and family relationships, mood, and sleep but also in dietary habits and physical activity. Additionally, participants who manifested higher levels of concern, isolation, sleep, or mood disturbances during lockdown also reported a worse impact in dietary habits. The existence of complex and bidirectional relationships between mental health, loneliness, sleep quality, dietary habits, and physical activity is well-recognized [10, 11, 13, 28-30]. These findings, however, pointed out the need for providing greater psychological support to individuals with obesity during this time, especially in those with preexisting conditions favoring higher anxiety and in those who have lesser family or social supportive networks. 
Telemedicine might represent a valuable alternative during this time or during other circumstances in when face to face contact is not possible. Indeed, previous studies have demonstrated similar efficacy of telemedicine when compared to personal contact in both anxiety and obesity management $[31,32]$.

Finally, in our survey, personal history of BS only resulted in amelioration of changes in dietary habits and weight gain in those participants in which the operation was performed within the 2 years before the pandemic but not in those who underwent surgery more than 2 years before. Of note, changes reported by $\mathrm{BS}>2 \mathrm{y}$ participants in eating patterns were very similar to those reported by non-operated participants. In addition, the proportion of individuals reporting weight gain was even larger among the $\mathrm{BS}>2 \mathrm{y}$ group than for the non-BS group.

The short- and long-term impact of BS on dietary habits, food preferences, and eating behavior is still a matter of debate. Some studies describe changes in food preferences after BS with increased preference for fewer calorically dense and carbohydrate-rich foods, while others describe opposite findings [33]. Eating disorders including binge-eating disorder and emotional eating are quite common among BS candidates [34]. While eating pathology typically improves in the short term following BS, the long-term sustainability is controversial [34-38]. Lockdown conditions may represent an exceptional situation; however, data reported herein stresses the importance of emotional well-being in the maintenance of healthy lifestyles, dietary control, and body weight in the mid and long term after BS. Additionally, it illustrates the need for continuous monitoring and health care in individuals with past history of BS.

Our study has many limitations. The most important is that behavioral, alimentary, and weight changes were self-reported and based on patient's own perception. This may be especially relevant for changes in body weight. Another limitation was that response rate was $49 \%$. Thus, we cannot exclude the existence of a non-response bias. The low percentage of participants who selected to report their current BMI precluded a deeper evaluation of the relationship between the degree of obesity and outcome variables.

In conclusion, we found that in individuals with current or past obesity, confinement was related to high levels of psychological distress and negative changes in dietary behaviors which resulted in or contributed to weight gain in a large proportion of the sample. Higher psychological distress was related to more severe eating disturbances, while only those who underwent BS in the past 2 years, but not those operated more than 2 years before, were partially protected for changes in dietary habits and weight gain. This data may help clinicians and health providers prepare for future prevention and treatment protocols for individuals with obesity during future health crisis.
Supplementary Information The online version contains supplementary material available at https://doi.org/10.1007/s11695-021-05225-z.

Acknowledgements The authors like to acknowledge the Patient Experience Forum, Hospital Clinic de Barcelona, for the initiative and support carrying out this study.

\section{Declarations}

Competing Interests/Conflict of Interest The authors declare no competing interests.

\section{References}

1. Pascarella G, Strumia A, Piliego C, et al. COVID-19 diagnosis and management: a comprehensive review. J Intern Med. 2020;288: 192-206.

2. Wang Y, Wang Y, Chen Y, et al. Unique epidemiological and clinical features of the emerging 2019 novel coronavirus pneumonia (COVID-19) implicate special control measures. J Med Virol. 2020;92:568-76.

3. Francis HM, Stevenson RJ, Oaten MJ, et al. The immediate and delayed effects of TV: impacts of gender and processed-food intake history. Front Psychol. 2017;8:1616.

4. Moynihan AB, van Tilburg WA, Igou ER, et al. Eaten up by boredom: consuming food to escape awareness of the bored self. Front Psychol. 2015;6:369.

5. Cellini N, Canale N, Mioni G, et al. Changes in sleep pattern, sense of time and digital media use during COVID-19 lockdown in Italy. J Sleep Res. 2020:e13074.

6. Mazza C, Ricci E, Biondi S, et al. A nationwide survey of psychological distress among Italian people during the COVID-19 pandemic: immediate psychological responses and associated factors. Int J Environ Res Public Health. 2020;17

7. Ozamiz-Etxebarria N, il-Santamaria M, Picaza-Gorrochategui M, et al. Stress, anxiety, and depression levels in the initial stage of the COVID-19 outbreak in a population sample in the northern Spain. Cad Saude Publica. 2020;36:e00054020.

8. Wang C, Pan R, Wan X, et al. Immediate Psychological Responses and Associated Factors during the Initial Stage of the 2019 Coronavirus disease (COVID-19) epidemic among the general population in China. Int J Environ Res Public Health. 2020;17

9. Wolf MS, Serper M, Opsasnick L, et al. Awareness, attitudes, and actions related to COVID-19 among adults with chronic conditions at the onset of the U.S. Outbreak: A Cross-sectional Survey. Ann Intern Med. 2020;

10. Xiao H, Zhang Y, Kong D, et al. Social capital and sleep quality in individuals who self-isolated for 14 days during the coronavirus disease 2019 (COVID-19) outbreak in January 2020 in China. Med Sci Monit. 2020;26:e923921.

11. Cardi V, Leppanen J, Treasure J. The effects of negative and positive mood induction on eating behaviour: a meta-analysis of laboratory studies in the healthy population and eating and weight disorders. Neurosci Biobehav Rev. 2015;57:299-309.

12. Gluck ME. Stress response and binge eating disorder. Appetite. 2006;46:26-30.

13. Hawkley LC, Thisted RA, Cacioppo JT. Loneliness predicts reduced physical activity: cross-sectional \& longitudinal analyses. Health Psychol. 2009;28:354-63.

14. Roberts CJ, Campbell IC, Troop N. Increases in weight during chronic stress are partially associated with a switch in food choice towards increased carbohydrate and saturated fat intake. Eur Eat Disord Rev. 2014;22:77-82. 
15. Torres SJ, Nowson CA. Relationship between stress, eating behavior, and obesity. Nutrition. 2007;23:887-94.

16. Ammar A, Brach M, Trabelsi K, et al. Effects of COVID-19 home confinement on eating behaviour and physical activity: results of the ECLB-COVID19 international online survey. Nutrients. 2020;12

17. Di RL, Gualtieri P, Pivari F, et al. Eating habits and lifestyle changes during COVID-19 lockdown: an Italian survey. J Transl Med. 2020;18:229.

18. Rodríguez-Pérez C, Molina-Montes E, Verardo V, et al. Changes in dietary behaviours during the COVID-19 outbreak confinement in the Spanish COVIDiet Study. Nutrients. 2020;12

19. Scarmozzino F, Visioli F. Covid-19 and the subsequent lockdown modified dietary habits of almost half the population in an Italian sample. Foods. 2020;9

20. Sidor A, Rzymski P. Dietary choices and habits during COVID-19 lockdown: experience from Poland. Nutrients. 2020;12

21. Simon GE, Von KM, Saunders K, et al. Association between obesity and psychiatric disorders in the US adult population. Arch Gen Psychiatry. 2006;63:824-30.

22. Rubino F, Cohen RV, Mingrone G, et al. Bariatric and metabolic surgery during and after the COVID-19 pandemic: DSS recommendations for management of surgical candidates and postoperative patients and prioritisation of access to surgery. Lancet Diabetes Endocrinol. 2020;8:640-8.

23. Almandoz JP, Xie L, Schellinger JN, et al. Impact of COVID-19 stay-at-home orders on weight-related behaviors among patients with obesity. Clin Obes. 2020:e12386.

24. Asmundson GJG, Taylor S. Coronaphobia: fear and the 2019nCoV outbreak. J Anxiety Disord. 2020;70:102196.

25. Caussy C, Pattou F, Wallet F, et al. Prevalence of obesity among adult inpatients with COVID-19 in France. Lancet Diabetes Endocrinol. 2020;8:562-4.

26. Palaiodimos L, Kokkinidis DG, Li W, et al. Severe obesity, increasing age and male sex are independently associated with worse inhospital outcomes, and higher in-hospital mortality, in a cohort of patients with COVID-19 in the Bronx, New York. Metabolism. 2020;108:154262.

27. Richardson S, Hirsch JS, Narasimhan M, et al. Presenting characteristics, comorbidities, and outcomes among 5700 patients hospitalized with COVID-19 in the New York City area. JAMA. 2020;323:2052-9.

28. Chua JL, Touyz S, Hill AJ. Negative mood-induced overeating in obese binge eaters: an experimental study. Int J Obes Relat Metab Disord. 2004;28:606-10.

29. Dashti HS, Scheer FA, Jacques PF, et al. Short sleep duration and dietary intake: epidemiologic evidence, mechanisms, and health implications. Adv Nutr. 2015;6:648-59.

30. Henriksen RE, Torsheim T, Thuen F. Loneliness, social integration and consumption of sugar-containing beverages: testing the social baseline theory. PLoS One. 2014;9:e104421.

31. Huang JW, Lin YY, Wu NY. The effectiveness of telemedicine on body mass index: a systematic review and meta-analysis. J Telemed Telecare. 2019;25:389-401.

32. Morriss R, Patel S, Malins S, et al. Clinical and economic outcomes of remotely delivered cognitive behaviour therapy versus treatment as usual for repeat unscheduled care users with severe health anxiety: a multicentre randomised controlled trial. BMC Med. 2019;17: 16.

33. Al-Najim W, Docherty NG, le Roux CW. Food intake and eating behavior after bariatric surgery. Physiol Rev. 2018;98:1113-41.

34. Brode CS, Mitchell JE. Problematic eating behaviors and eating disorders associated with bariatric surgery. Psychiatr Clin North Am. 2019;42:287-97.

35. Devlin MJ, King WC, Kalarchian MA, et al. Eating pathology and experience and weight loss in a prospective study of bariatric surgery patients: 3-year follow-up. Int J Eat Disord. 2016;49:1058-67.

36. Devlin MJ, King WC, Kalarchian MA, et al. Eating pathology and associations with long-term changes in weight and quality of life in the longitudinal assessment of bariatric surgery study. Int J Eat Disord. 2018;51:1322-30.

37. Kalarchian MA, King WC, Devlin MJ, et al. Psychiatric disorders and weight change in a prospective study of bariatric surgery patients: a 3-year follow-up. Psychosom Med. 2016;78:373-81.

38. Meany G, Conceição E, Mitchell JE. Binge eating, binge eating disorder and loss of control eating: effects on weight outcomes after bariatric surgery. Eur Eat Disord Rev. 2014;22:87-91.

Publisher's Note Springer Nature remains neutral with regard to jurisdictional claims in published maps and institutional affiliations.

\section{Affiliations}

\section{Amanda Jimenez ${ }^{1,2,3} \cdot$ Ana de Hollanda ${ }^{1,2,3} \cdot$ Eva Palou $^{4} \cdot$ Emilio Ortega $^{2,3,5} \cdot$ Alba Andreu $^{1} \cdot$ Judit Molero $^{1}$. Carla Mestre $^{1}$ - Ainitze Ibarzabal ${ }^{1}$ - Amadeu Obach ${ }^{1} \cdot$ Lilliam Flores $^{1,2,6} \cdot$ Silvia Cañizares $^{1}$ • Jose Maria Balibrea ${ }^{1}$. Josep Vidal ${ }^{1,2,6}$. Joan Escarrabill ${ }^{4}$. Violeta Moize ${ }^{1,2,6}$ (D)}

1 Obesity Unit, Hospital Clínic de Barcelona, c/Villarroel 170, 08036 Barcelona, Spain

2 Institut d'Investigacions Biomèdiques August Pi Sunyer (IDIBAPS), c/ Rosellon, 149, 153, 08036 Barcelona, Spain

3 Centro de Investigación Biomédica en Red de Obesidad y Nutrición (CIBEROBN), Instituto de Salud Carlos III, C/ Monforte de Lemos 3-5.Pabellón 11. Planta 0, 28029 Madrid, Spain
4 Patient Experience Forum, Hospital Clínic de Barcelona, c/Villarroel 170, 08036 Barcelona, Spain

5 Endocrinology Department, Hospital Clínic de Barcelona, c/ Villarroel 170, 08036 Barcelona, Spain

6 Centro de Investigación Biomédica en Red de Diabetes y Enfermedades Metabólicas Asociadas (CIBERDEM), Instituto de Salud Carlos III, C/ Monforte de Lemos 3-5.Pabellón 11. Planta 0, 28029 Madrid, Spain 